\title{
ROLE OF BIOSPHERE RESERVES IN RESEARCH, MONITORING, TRAINING, EDUCATION, PUBLIC AWARENESS AND OUTREACH ACTIVITIES
}

\author{
I.A.U.N. GUNATILLEKE and C.V.S. GUNATILLEKE* \\ Department of Botany, University of Peradeniya, Sri Lanka.
}

\author{
Proceedings of the South and Central Asian MAB Meeting of Experts on \\ Environmental Conservation, Management and Research, Hikkaduwa, Sri Lanka \\ 15-18 October 2002
}

\begin{abstract}
Summary: The Seville strategy for biosphere reserves recommends their use for research, monitoring, education and training at international, regional, national and individual biosphere levels in fulfilling objectives of conservation and sustainable development. At international or regional level, a network of strategically selected biosphere reserves from among participating countries could develop long-term biological, environmental and socio-economic research and monitoring programmes on mutually acceptable standardized protocols. The South and Central Asian region, rich in biological and cultural diversity, could take a lead role in developing and implementing management strategies for a network of biosphere reserves with a judicious blend of proven traditional knowledge and a modern scientific approach. Among the priority studies suggested are those on the oceans and atmosphere, such as contributions to climate change and carbon dynamics, impacts of El Nino Southern Oscillation (ENSO) and trans-boundary pollution including the brown dust cloud and forest die back and on the organisms therein such as migratory birds, sea turtles, whales, invasive exotics, etc. Standardizing the natural resource economic parameters and methodologies, taking into consideration the eastern culture and perceptions towards nature, is also another area of regional research interest.
\end{abstract}

In instances where trans-boundary biodiversity hotspots of global significance are found, as in the cases of Sri Lanka and the Western Ghats of India, co-ordinated and collaborative research and training programmes should be promoted. Inventorying of biodiversity and associated cultural diversity will provide scientific underpinning for the establishment of a network of biosphere reserves at national level and clustering and linking the fragmented conservation areas according to the biosphere reserve concept. Individual biosphere reserves can be the foci of research, training, education and extension activities through inter-institutional collaboration, thus pooling their expertise. In this manner, the biosphere reserves can be model sites where conservation and sustainable development supported by research, education, training and extension are carried out.

\section{Introduction}

Biosphere reserves form an international network of representative examples of the world's ecosystems intended to fulfil three complementary, yet integrated functions, viz., i) conservation, to preserve genetic resources, species, ecosystems and landscapes; ii) a development function, to foster sustainable economic and human

\footnotetext{
" Corresponding author
} 
development and iii) a logistic support function, to support demonstration projects, environmental education, training, research and monitoring, related to local, national and global issues of conservation and sustainable development. Biosphere reserves are regarded as exemplary landscapes, where the 'ecosystem approach', adopted by the Conference of the Parties to the Convention on Biological Diversity as the primary framework for action under the Convention, could be explored. An ecosystem approach is based on the application of appropriate scientific methodologies focused on levels of biological organisation, which encompasses the essential structure, processes, functions and interactions among organisms and the environment. It also recognises that humans, with their cultural diversity, are an integral component of many ecosystems ${ }^{10}$ (Fig.1). Therefore, biosphere reserves could serve as instruments which can contribute to the implementation of the Convention on Biological Diversity and to the establishment of a global ecological monitoring system.

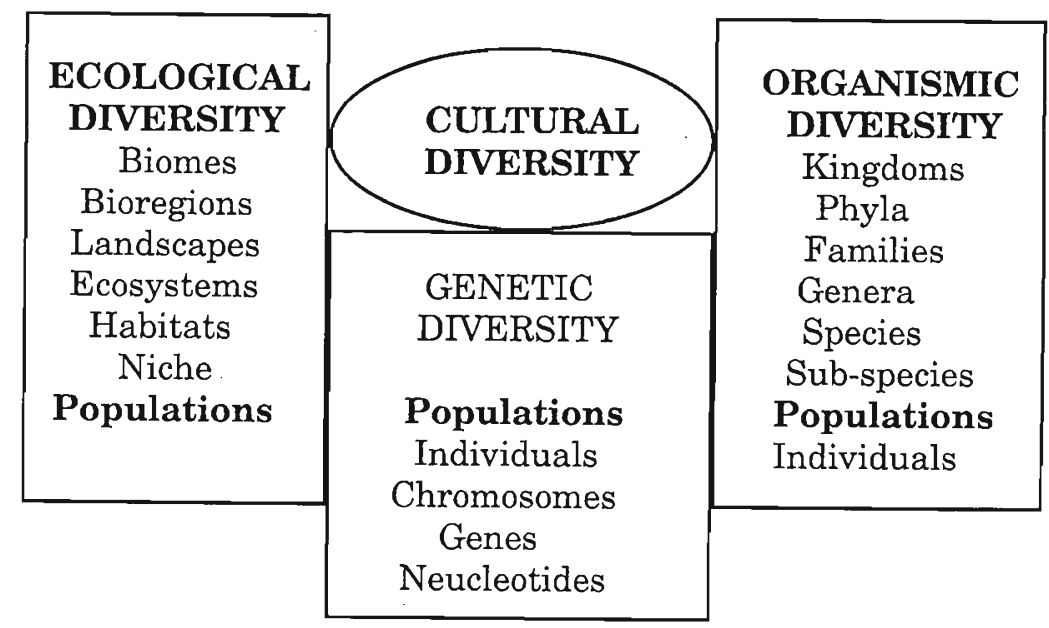

Figure 1: Composition and Levels of Biodiversity (Adapted from UNEP, 1995)

Physically, each biosphere reserve should contain three elements: i) one or more securely protected core areas for conserving biological diversity; these core areas could be used for monitoring minimally disturbed ecosystems, non-destructive research and other low-impact uses (such as education); ii) a clearly identified buffer zone, which usually surrounds or adjoins the core areas that could be used for cooperative activities compatible with sound ecological practices, including environmental education, recreation, ecotourism and basic and applied research; and iii) a flexible transition area, or an area of co-operation, which may contain a variety of agricultural activities, settlements and other uses and in which local communities, management agencies, scientists, non-governmental organisations, cultural groups, economic interests and other stakeholders work together to manage and sustainably develop the area's resources. Although originally envisioned as a 
series of concentric rings, the three zones have been implemented in many different ways in order to meet local needs and conditions. In fact, one of the greatest strengths of the biosphere reserve concept has been the flexibility and creativity with which it has been realized in various situations. ${ }^{9}$

Some of the key elements in implementing the innovative concept of the biosphere reserve include, reinforcement of scientific research, monitoring, training and education, in order to further understand humanity's relationships with the natural world. This could be done through programmes of public awareness, information sharing and formal and informal education, based on long-term, intergenerational perspectives.

The Seville Strategy ${ }^{9}$ identifies the specific role of biosphere reserves in developing a new vision of the relationship between conservation and development, encapsulating the ideas of UNCED (Agenda 21) for promoting both conservation and sustainable development. Among its major recommendations for implementation at international, regional, national and biosphere levels are the following:

- Use biosphere reserves to conserve natural and cultural diversity,

- Utilize biosphere reserves as models of land management and of approaches to sustainable development,

- Use biosphere reserves for research, monitoring, education and training,

- Implement the biosphere reserve concept.

In this presentation, we intend to discuss the role of biosphere reserves in fulfilling the logistic support function in research, monitoring, education, training and outreach activities, in conformity with the Seville recommendations. Providing scientific information to guide nature conservation and sustainable development is an essential ingredient of the biosphere reserve concept, and providing opportunities for research and a logistic base for research and monitoring are key functions of biosphere reserves.

\section{Role of Biosphere Reserves at International/Regional Level for Research, Monitoring, Education and Training:}

The Seville Strategy has recommended the following actions for the use of biosphere reserves for research, monitoring, education and training at international, regional or inter-regional level.

Taking into account the long-term environmental as well as socio-economic research at international and regional level, each country in the South and Central Asian MAB network may consider such research and monitoring activities as required for the fulfilment of their respective country obligations to the CBD and other international conventions (e.g. Ramsar, Bonn) and strategies (e.g. Seville) in 
selected biosphere reserves, as decided by their own National MAB Committees and other relevant bodies. However, an agreement on a common protocol for each such study would enable not only comparisons among the selected sites within our region, but would also place us in a position to contribute our regional trends to the global scenario. Regional meetings of experts and the establishment of networking among the National MAB Committees in the region will greatly facilitate planning and implementation of these activities.

\section{Recommendations of the Seville Strategy at International level}

\section{A) Improve knowledge of the interactions between humans and the biosphere.}

$i \quad$ Use the World Network of Biosphere Reserves to conduct comparative environmental and socio-economic research, including long-term research that will require decades to complete.

ii Use the World Network of Biosphere Reserves for international research programmes that deal with topics such as biological diversity, desertification, water cycles, ethnobiology and global change.

iii Use the World Network of Biosphere Reserves for co-operative research programmes at the regional and inter-regional levels, such as those existing for the Southern Hemisphere, East Asia and Latin America.

iv Encourage the development of innovative, interdisciplinary research tools for biosphere reserves, including flexible modelling systems for integrating social, economic and ecological data.

$v$ Develop a clearing house for research tools and methodologies in biosphere reserves.

vi Encourage interactions between the World Network of Biosphere Reserves and other research and education networks, and facilitate the use of the biosphere reserves for collaborative research projects of consortia of universities and other institutions of higher learning and research, in the private as well as public sector, and at non-governmental as well as governmental levels.

\section{B) Improve monitoring activities:}

$i$ Use the World Network of Biosphere Reserves, at international, regional, national and local levels, as priority long-term monitoring sites for international programmes focussed on topics such as terrestrial and marine observation systems, global change, biodiversity, and forest health. 
ii Encourage the adoption of standardized protocols for meta-data concerning the description of flora and fauna, to facilitate the interchange, accessibility and utilization of scientific information generated in biosphere reserves.

\section{C) Improve education, public awareness and involvement}

$i \quad$ Facilitate exchange of experience and information between biosphere reserves, with a view to strenthening the involvement of volunteers and local people in biosphere activities.

ii Promote the development of communication systems for diffusing information on biosphere reserves and on experiences at the field level.

\section{D) Improve training for specialists and managers}

$i \quad$ Utilize the World Network of Biosphere Reserves to support and encourage international training opportunities and progrmmes.

ii Identify representative biosphere reserves as regional training centres.

As a case in point, I wish to take an example from the pan-tropical network of Forest Dynamics Plots (FDPs) initiated under the Centre for Tropical Forest Science of the Smithsonian Tropical Research Institute. At present, over 13 such FDPs have been established in nine countries across the tropics, where standardised methodology in monitoring, sampling and data analysis is being followed. There are now more than two million trees of over 4,000 species in this mega-data base. Currently, data from these plots are being used to better understand the origin and maintenance of species diversity, focussing primarily on the association between species distributions and diversity with habitat types. ${ }^{6}$ Based on these trans-network studies, it has been possible to predict with greater confidence that size distributions of trees in tropical forests are remarkably constant in their shapes across climatically and topographically varied sites, suggesting that they are determined by general underlying principles of community organisation (Muller-Landau et al. unpublished). This is one of the world's largest tropical tree data sets, based on regular censusing and updating. Consequently, it has an enormous potential in testing general principles/theories in community ecology, addressing issues related to community changes and nutrient pools and fluxes with predicted long-term changes in the global climate, and assisting in preparing global/regional scale models. Longterm ecological research and monitoring of this nature has the potential and the capability to address a wide range of topics related to the interactions of living organisms and their biotic and abiotic environment. Within our region, the Sinharaja Biosphere Reserve in Sri Lanka and the Mudumalai Wildlife Reserve in India, are members of this CTFS network of FDPs. 
Another similar network is the Tropical Soil Biology and Fertility (TSBF) programme, initiated in the early nineties as a component project of the International Union of Biological Sciences (IUBS) programme, the Decade of the Tropics Programme and of the Man and the Biosphere Programme of UNESCO, in which a number of Indian study sites and the Sinharaja from Sri Lanka were featured from our region. ${ }^{11}$ The objective of the TSBF programme was to "determine the management options for improving tropical soil fertility through the manipulation of biological processes'. The concepts on which this programme was based were that the fertility of tropical soils is controlled by biological processes and can be managed by the manipulation of soil organic matter, nutrient-use efficiency, soil water regime and soil fauna. A minimum suite of physico-chemical, biological and socio-economic studies were agreed upon by the participating tropical (and sub-tropical) countries ${ }^{5}$ and a number of manipulative experiments on one or more of the above themes were conducted on the participating sites. ${ }^{11}$ Based on these studies, syntheses on the potential role of each of the above factors on the management of soil biological processes, modelling soil organic dynamics and plant productivity in tropical ecosystems, integrating process research and farm practice together and finally a case study of the Jhum agro-ecosystem in NE India, were documented. It was a research attempt of the 'ecosystem approach' to sustainable development and the concluding paragraph of the case study chapter is worth repeating here: 'Linking traditional knowledge with scientific research on soil biological processes will provide the framework for basing soil management practices on a value system that farmers understand and appreciate. This will encourage farmers to participate in the (sustainable) development process itself. ${ }^{8}$

The establishment of a network among the National Committees of the region is on the agenda for discussion at this meeting. As such, some consideration should be given to prioritise research activities of regional importance, which require longterm monitoring in the biosphere reserves of the member countries on mutually agreed protocols. Monitoring the levels of green-house gases in strategically located reserves, preferably in biosphere reserves, using standardized protocols, studies on plant and animal communities, animal migration (both terrestrial and marine species), socio-economics, restoration and rehabilitation, are some studies which may benefit from inter-site comparisons. The South and Central Asian region had a civilization sustained by agriculture, with ancient water harvesting and irrigation technologies and spanning over millennia. At the same time, it was imbued with strong conservation ethics, influenced by spiritual values. It is time now to initiate sharing experiences on combining the proven traditional knowledge with modern scientific research, in a judicious blend acceptable to the farmer communities. The South and Central Asian region, with such a rich cultural and biological heritage, could take a lead role in managing appropriately zoned biosphere reserves, with community participation, to fulfil the three complementary functions of the MAB concept viz., conservation, sustainable development and logistic support function. Thereby, we could be potential role models to the other regions. 
Inter-regional studies on a long-term basis, among marine and coastal biosphere reserves, such as coral reefs, mangroves, sea grass beds, among global/ regional commons as depicted by oceans and atmosphere and among threatened organisms like migratory birds, sea turtles, whales, dolphins which move freely in common and shared environments and are governed by international conventions in some cases (Ramsar, Bonn etc.) would be extremely beneficial from a conservation point of view. They could also contribute to non-destructive developmental activities such as nature and culture based tourism. Co-ordinated inter-site comparisons on the impact of pollution on selected terrestrial and marine biosphere reserves within our region would be more effective, timely and most appropriate. The impact of global phenomena such as El Nino Southern Oscillation (ENSO) and within our region that of the thick brown dust cloud in the skies are again, urgent issues that need regional co-operation. Biosphere reserves are indeed excellent sites for the generation of long-term base line information on such phenomena. With suitably established permanent plots and appropriately designed experimental protocols, as exemplified by the FDPs of the CTFS network or the TSBF programme, the two that we are most familiar with, the impact of these phenomena on our rich biological diversity, which is partly unique to individual countries and partly shared among countries, could be monitored and researched upon. These studies may even act as early warning systems on any disturbing trends in the regional climate and biodiversity. The respective governments and associations of regional co-operation (e.g. SAARC) could then be alerted about them, so that remedial action and corrective measures, if any, could be taken to reverse these trends.

Natural resource economics is another area of research that has received much attention (and some criticism too) in recent times. Across site valuation of the buffer and transition zone communities of the biosphere reserves of the South and Central Asian region, should be done using methods developed in a western milieu, but adapted to suit us in this region. In doing so, the strong eastern value systems and long-established conservation ethics fostered by strong religious traditions would not be ignored. Studies of this nature would also yield valuable information, with direct policy implications, that would help among others, in rationalising international and national aid and loan programmes. Rural sociological studies in the buffer zones and transition zones will provide most of the basic information needed for resource economic surveys.

Within the South Asian region, Sri Lanka and the Western Ghats of India are together considered as one of the 25 hotspots of biodiversity in the world. ${ }^{7} \mathrm{~A}$ considerable proportion of plant species are shared between these two regions due to their historical biogeographic associations, resulting from past geological phenomena. ${ }^{1,2}$ Similarities also exist in their socio-cultural histories. Naturally, cooperative and coordinated research programmes among selected biosphere reserves in these two globally important biodiversity hotspot regions, would help to address the common issues that affect their conservation and sustainable management. This 
can perhaps, expand to cover all countries of South and West Asia as the networking among the National MAB Committees and their activities get under way.

Longterm research on the management of weed species in core-areas of biosphere reserves, human-animal (e.g. elephants) conflicts, forest die-back in the mountain regions, restoration of degraded lands and development of analogue forests or forest gardens, simulating, as far as possible, the structure and functioning of the natural forest, development of models of community participation in landscape/ seascape management, including marketing of their sustainable produce, are areas of immense research potential with mutual benefit.

Much of what has already been stated in relation to recommendations at international level are also relevant in addressing the recommendations at national and regional level. However, in most countries in the region, the remaining natural vegetation is much fragmented, degraded and exists as islands in a sea of anthropogenically modified and built up landscapes. Therefore, the long-term survival of species and the maintenance of genetic diversity of threatened species in this fragmented landscape is at great risk. Therefore, it is of urgent scientific interest to find means to arrest species extinction and genetic erosion. ${ }^{3}$ Establishment of additional national MAB reserves and linking them with other protected areas through 'species and gene corridors of mixed species plantations', forest gardens, nature parks, road and stream reservations through which 'mobile links' of animal pollinators and seed dispersers can be effectively sustained, would be of considerable interest at national and regional level policy planning.

\section{Role of Biosphere Reserves at National Level for Research, Monitoring, Education and Training:}

\section{Recommendation of the Seville Strategy at National Level}

$i \quad$ Integrate biosphere reserves with national and regional scientific research programmes, and link these research activities to national and regional policies on conservation and sustainable development.

ii Encourage the participation of biosphere reserves in national programmes of ecological and environmental monitoring and development of linkages between biosphere reserves and other monitoring sites and networks.

iii Include information on conservation and sustainable use, as practised in biosphere reserves, in school programmes and teaching manuals, and in media efforts.

iv Encourage participation of biosphere reserves in international networks and programmes, to promote cross-cutting linkages in education and public awareness. 
$v \quad$ Define the training needed by biosphere managers in the $21^{\text {st }}$ century and develop model training programmes on such topics as how to design and implement inventory and monitoring programmes in biosphere reserves, how to analyse and study socio-cultural conditions, how to solve conflicts, and how to manage resources co-operatively in an ecosystem or landscape context.

In Sri Lanka, considerable effort has been taken to estimate the existing biodiversity, using a number of key groups of biota and the hydrological value of all the remaining natural forests larger than 200ha in size through a biodiversity inventory project of the Forest Department carried out by the World Conservation Union and the World Conservation Monitoring Centre with funding from the FAO/ UNDP. Similarly, the Department of Wildlife Conservation has established a complementary network of both terrestrial and marine protected area systems, to which new sites are added or existing ones upgraded as become necessary in implementing the national policies on conservation and sustainable development. Formation of integrated clusters of protected areas such as the Peak-Wilderness/ Bambarabotuwa/Eratne-Gilimale cluster, Sinharaja, Kanneliya-DediyagalaNakiyadeniya and adjacent forests, Pedro and Knuckles/Wasgomuwa, for the conservation of indigenous biodiversity has been recommended by this study and its implementation is well under way, at present.

At a recent workshop conducted to revise and update the existing list of National Biosphere Reserves, the information from the above survey as well as the long experience of many stakeholders, some with research and monitoring experience in proposed sites, was harnessed. In order to facilitate research, monitoring and education programmes in these national MAB reserves, establishment of field facilities for researchers and other visitors has also been recommended. Only the Sinharaja has so far received international recognition as a biosphere reserve, while two others have been nominated (Kanneliya and the Knuckles). Still others are being considered to be proposed as World Heritage Sites (Peak Wilderness and Horton Plains). In all these reserves, long-term sustained interest in research, monitoring and education to meet the conservation and development functions needs to be maintained.

Another area of considerable research and monitoring interest at national and regional level is the status and population dynamics of incumbent species in coastal and inland wetland ecosystems, which are again highly threatened in most countries in the region. In Sri Lanka, the man-made reservoir systems of large, medium and small size reservoirs interspersed among human habitations in the lowland seasonally dry agricultural areas, are the chosen habitats of wetland animal (especially water fowl) and plant species. The annual waterfowl count carried out in Sri Lanka over a period of many years by the Wildlife and Nature Protection Society has a strong database on this group of birds. This database may provide very useful information with respect to their population dynamics and habitat shifts over a 
long period of time. The village level reservoir, its catchment and its downstream agricultural area and the homesteads could be treated as a case study in sustainable development, using the ecosystem approach and MAB concepts. Monitoring studies of this nature could be coupled with education and training programmes for school children, naturalists and nature based tourism activities at regional and local levels. Plant-animal interactions and food webs of such local ecosystems are excellent field studies at local level with national level coordination.

We wish to elaborate on research, monitoring, education, public awareness and training conducted at individual reserve level, in accordance with the Seville Strategy, taking the Sinharaja Biosphere Reserve in Sri Lanka as an example we are most familiar with. The Sinharaja Biosphere Reserve has been used for basic (strategic) and applied (targeted) research with a focus on both local and regional issues with interdisciplinary projects with inter-institutional collaboration both within and outside Sri Lanka for nearly 25 years. A summary of the research activities carried out in the reserve is given in Fig. 2.

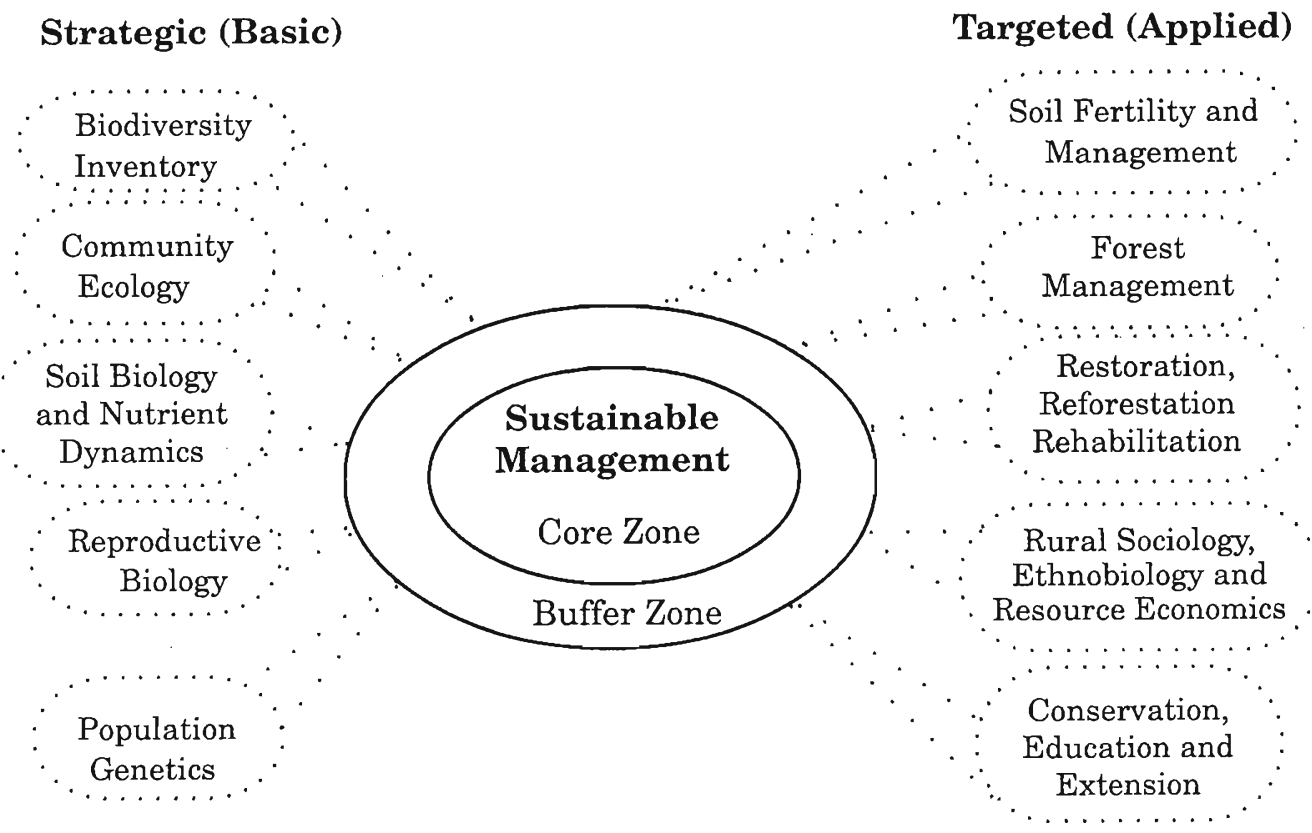

Figure 2: Inter-Disciplinary Research in Sinharaja and Surrounding Forests 


\section{Role of Biosphere Reserves at Individual Reserve Level for Research, Monitoring, Education, Public Awareness and Training:}

\section{Recommendation of the Seville Strategy at Biosphere Reserve Level}

$i \quad$ Use biosphere reserves for basic and applied research, particularly projects with a focus on local issues, interdisciplinary projects incorporating both the natural and the social sciences, and projects involving the rehabilitation of degraded ecosystems, the conservation of soils and water and the sustainable use of natural resources.

ii Develop a functional system of data management for rational use of research and monitoring results in the management of the biosphere reserve.

iii Use the reserve for making inventories of fauna and flora, collecting ecological and socio-economic data, making meteorological and hydrological observations, studying the effect of population, etc., for scientific purposes and as the basis for sound site management.

iv Use the reserve as an experimental area for the development and testing of methods and approaches for the evaluation and monitoring of biodiversity, sustainability and quality of life of its inhabitants.

$v \quad$ Use the reserve for developing indicators of sustainability (in ecological, economic, social and institutional terms) for the different productive activities carried out within the buffer zones and transition areas.

$v i$ Develop a functional system of data management for rational use of research and monitoring results in the management of the biosphere reserve.

vii Encourage involvement of local communities, school children and other stakeholders in education and training programmes and in research and monitoring activities within biosphere reserves.

viii Produce visitors' information about the reserve, its importance for conservation and sustainable use of biodiversity, its socio-cultural aspects, and its recreational and educational programmes and resources.

ix Promote the development of ecology field educational centres within individual reserves, as facilities for contributing to the education of school children and other groups.

$x \quad$ Use the reserve for on-site training and for national, regional and local seminars. 
xi Encourage appropriate training and employment of local people and other stakeholders to allow for their full participation in inventory, monitoring and research in programmes on biosphere reserves.

xii Encourage training programmes for local communities and other local agents (such as decision-makers, local leaders and agents working in production, technology transfer, and community development programmes) in order to allow for their full participation in the planning, management and monitoring process of biosphere reserves.

xiii Promote the development of ecology field educational centres within individual reserves, as facilities for contributing to the education of school children and other groups.

xiv Use the reserve for on-site training and for national, regoinal and local seminars.

Sinharaja, the country's largest and relatively less degraded lowland rain forest, is recognized as a National Heritage Wilderness Area, an International Man and the Biosphere Reserve and a World Heritage Site. It also plays a significant role within the Sri Lanka/Western Ghats hotspot of biodiversity, because it harbours a high proportion of the Sri Lankan endemic species, some with restricted distribution, within it. Its status over the years has changed from a wilderness with traditional mysticism to one of exploitation and again to one of conservation.

Research at Sinharaja, initiated with tree enumerations to estimate its timber potential, has been systematically expanded over the years into an interdisciplinary research programme, subsequent to its elevated protective status in the late 1970s. These studies include the phytosociology of its tree flora, restoration and regeneration ecology, soil biology and nutrient cycling, reproductive biology and genetic diversity of under-utilised species, ecology of birds and small mammals, long-term forest dynamics, rural sociology and resource economics. Sinharaja was one of the ten programme sites for the Tropical Soil Biology and Fertility Programme of UNESCO/ IUBS. It continues to be a member of the Long-Term Forest Dynamics Programme across the tropics, launched by the Centre for Tropical Forest Science of the Smithsonian Tropical Research Institution. ${ }^{4}$

Research information generated so far has not only enhanced the conservation value of this forest but also contributed towards its management for multiple uses. Sinharaja serves as an outdoor laboratory at all levels of education, especially at the secondary and tertiary levels. It is the most popular lowland rain forest for nature-based tourism in the country.

The research and monitoring results generated over the years need to be rationally used through the development of a functional system of data assimilation 
and synthesis, for better management of the biosphere reserve. Regional publications, based on case studies of the use of biosphere reserves in implementing the Seville Strategy, will help disseminate the knowledge gathered by multiple stakeholders.

With respect to the out-reach activities, especially for the buffer zone and transition zone communities around core areas of a biosphere reserve, they can be best planned by initial village level surveys of their needs to conform to the lifestyles compatible with conservation and sustainable development objectives. Again, a number of such initiatives are being described in detail in another paper titled 'Buffer zone of the Sinharaja Biosphere Reserve and its management strategies' at this meeting (Wijesooriya and Gunatilleke, unpublished).

\section{References}

1 Abeywickrama B.A. (1956). The origin and affinities of the flora of Ceylon. Proc. $11^{\text {th }}$ Ann. Sess. Ceylon Assoc. Adv. Sci. Part 2: 99-121.

2 Ashton P. S. \& Gunatilleke, C.V.S. (1987). New light on the plant geography of Ceylon I. Historical plant geography. Journal of Biogeography 14: 249-285.

3 Gunatilleke I.A.U.N. (1999). Reproductive Biology and Genetics of Selected Rainforest Plant Species of Sri Lanka: Implications for Conservation. (Presidential Address - Section D, 1998) Proc. 54 ${ }^{\text {th }}$ Ann. Sess. Sri Lanka Assoc. Adv. Sci., Part II: 95-122.

4 Gunatilleke C.V.S., Gunatilleke I.A.U.N. \& Ashton P.M.S. (1995). Rainforest research and conservation: the Sinharaja experience in Sri Lanka. Sri Lanka Forester 22(1\&2): 49-60.

5 Anderson J. M. \& Ingram J.S.I. (1989). Tropical Soil Biology and Fertility: A Handbook of Methods. Wallingford, UK: CAB International.

6 Losos E. (2002). Patterns of Forest Dynamics across a Global Network of Large-scale Plots. (Abstract). ATB Annual Meeting - Tropical Forests: Past, Present, Future. Panama City, p.67.

7 Myres N., Mittermeir R.A., Mittermeir C.G., da Fonseca G.A.B. \& Kent J. (2000). Biodiversity hotspots for conservation priorities. Nature 403 No. 6772: 853-858.

8 Ramakrishnan P. S. (1994). The Jhum agroecosystem in northeastern India: A case study of the biological management of soils in a shifting agricultural system. In: The Biological Management of Tropical Soil Fertility, Woomer P.L. and Swift M.J. (Eds.). John Wiley and Sons, New York. 189-208. 
9 UNESCO (1996). Biosphere Reserves: The Seville Strategy and the Statutory Framework of the World Network. UNESCO, Paris, $18 \mathrm{pp}$.

10 UNESCO (2002). Biosphere Reserves: Special places for people and nature, UNESCO, Paris, 208 pp.

11 Woomer P.L. \& Swift M.J. (1994). The Biological Management of Tropical Soil Fertility, John Wiley and Sons, New York, 243 pp. 